IRA-International Journal of Education \& Multidisciplinary Studies

ISSN 2455-2526; Vol.07, Issue 02 (2017)

Pg. no. 89-98

Institute of Research Advances

http://research-advances.org/index.php/IJEMS

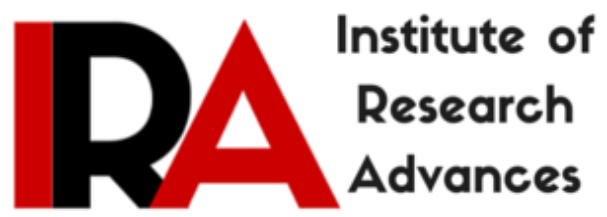

\title{
What Is Meant by Cognitive Structures? How Does It Influence Teaching -Learning of Psychology?
}

\author{
C. Girija Navaneedhan ${ }^{1}$, T. J. Kamalanabhan ${ }^{2}$ \\ ${ }^{1}$ Post-Doctoral Fellow, Indian Institute of Technology, Madras, Chennai, India. \\ ${ }^{2}$ Professor \& H.O.D, Indian Institute of Technology, Madras, Chennai, India.
}

Type of Review: Peer Reviewed.

DOI: http://dx.doi.org/10.21013/jems.v7.n2.p5

\section{How to cite this paper:}

Navaneedhan, C., \& Kamalanabhan, T. (2017). What Is Meant by Cognitive Structures? How Does It Influence Teaching -Learning of Psychology?. IRA International Journal of Education and Multidisciplinary Studies (ISSN 2455-2526), 7(2), 89-98. doi:http://dx.doi.org/10.21013/jems.v7.n2.p5

\section{(C) Author.}

\section{(cc) EY-NC}

This work is licensed under a Creative Commons Attribution-Non Commercial 4.0 International License subject to proper citation to the publication source of the work.

Disclaimer: The scholarly papers as reviewed and published by the Institute of Research Advances (IRA) are the views and opinions of their respective authors and are not the views or opinions of the IRA. The IRA disclaims of any harm or loss caused due to the published content to any party. 


\begin{abstract}
Cognitive structures are the basic mental pattern people use to process any information. Metaphorical thinking being one of the mental tool present innate in human beings which when practiced consciously could help developing cognitive structures in turn help to process information. According to Jean Piaget and William Perry learning is facilitated by the mechanism comprising symbolic representations of the mental processes that is actively constructed by the learners based on the existing cognitive structures. Therefore, teaching/learning process should focus on the development of existing intellectual framework. Unlike the behaviourist approach, knowledge is acquired by the learner through intentional mental representations derived from past learning experiences. Teacher's role is to facilitate the learners with resources to build new knowledge to old and to modify the old to accommodate the new. The present paper focuses on how cognitive structures help in processing information by implementing metaphorical thinking statements in teaching/leaning process.
\end{abstract}

Key words: Cognitive structure, Metaphorical thinking, Mental Representations, Intellectual framework and Teaching/Learning process.

\title{
Role of Cognitive structures in Information Processing Ability
}

Cognitive structures play an important role in the information processing ability of the learners as they serve as frames of reference, allow grasping and working with one or several aspects of a concept. Therefore, teacher plays an important role in facilitating the learners to develop mental representations by illustrating the content with graphical representation, visualization of diagrams as well as through symbolic and abstract thinking. Greater is the number of illustrations greater is the mental representation and quicker is the information processing ability of the individuals. A mental representation depends on individual's capacity to "concretely" represent a concept to oneself by several mental frames of reference. This would switch between the mental frames according to the specific situation during problem-solving. Building mental frames consciously is the important step in processing the given information. Transfer of information between several mental representations could be gained by experience if an individual is working on a one particular concept. With further experience, the representations may be linked together in the mind. Regular practice of mental representations results in development of intuition in that knowledge domain. A mental representation of the given information depends on three cognitive processes namely: Generalizing, Synthesizing and Abstracting.

In the generalising step of information process of the content the role of the teacher is to provide innumerable of analogies to connect the old context with the new which would result in knowledge growth as the old knowledge serves as a template for the new.

In syntheses the information is combined as a whole in the context of learning, If an individual concentrates on the second phase of cognitive process more is the potential for synthesis in a field of knowledge, the more "compressible" the knowledge is that is merging and combining of things in the mind of the learner into a single, greater whole for example if the teacher wants to develop the concept of the word animal, she/he could show the pictures of two or three animals varying in their size so that the learner understand the concept animal by merging the features of the body parts and coming to the conclusion that word animal describes the living organism that grows horizontally.

In abstraction, the information being linked to both generalization and synthesis has the potential for both. It is however a different mental process, building new mental structures to match and model the structures studied, with an emphasis on the relations between the objects of thought rather than a focus on the objects themselves. For example, "the student is required to focus on the relationships that exist between an apple and an orange has to focus on the thinking that involves similarities and differences between them rather than focusing on the object.

The three basic steps involved in mental representation of the given information are 
$>$ The mental representations may be changed, adjusted to match the information to get desirable behavioural outcome.

$>$ The mental representation does not change over a time meaning that the existing information persists.

$>$ The new information is retained along with the retention of old mental representation from which it was built.

Therefore, a good, proper learning - involves mental activity that is not purely intuitive but also cognitive dealing with an input solely references the concept image in order to produce an output.

\section{Role of metaphorical thinking in developing cognitive structures}

Betty Garner (2012)suggested that the teachers while teaching everyday lessons to help students develop more effective cognitive structures to learn how to learn so they can make sense of what is taught. For that the teacher should understand that the basic cognitive structures as mental schema that an individual develops in relation to the bits of data to process information for meaning. For example, when an individual is confronted with unfamiliar information the first thing he/she would attempt is to recognize something about it that fits with prior knowledge and experience. As soon as the teacher enters the class, if he/ she puts the question "What do you notice?" the teacher is asking them to connect unfamiliar with familiar data. For example a teacher wishes to teach maths table she/ he should initiate the cognitive structure of memorization of tables by showing visual representation as follows

$2 * 1=2 \quad$ is same as the representation of number 2 as one time which is equal to 2

$2 * 2=4$ is same as the representation of number 2 as two times which is equal to 4

$2 * 3=6$ is same as the representation of number 2 as three times which is equal to 6

$2 * 4=8$ is same as representation of number 2 as four times which is equal to 8

The teacher should encourage the learners to process information by comparing how bits of data are alike and different by using the cognitive structure of conservation of constancy similar to the way Jean Piaget demonstrated cognitive constructivism to seven year old children by pouring water into wide mouthed container and transferred the same amount to a narrow mouthed container expecting them to understand that only the shape of the container changed but the volume of the water remained the same.

When a teacher teaches characteristics of Carbon compounds he/ she should start from the root starting with basic information about its natural existence and comparing its presence in large number of manmade compounds. This comparison would result in the development of cognitive structure Metaphorical thinking enables individuals to think outside the box by comparing bits of information that appear dissimilar but help us to create insights and original thinking. Therefore, thinking metaphorically in a conscious manner develops basic cognitive structures, which operate so automatically that the learners are not even aware of them. On other hand there are a few students who are incapable of forming effective cognitive structures, such students often drop out of school mentally as early as third grade and survive the upper grades by trying to do just enough to get by or memorizing to pass They should be taught to develop the cognitive structures they need to learn how to learn. Earlier literature has shown the application of metaphors in knowledge development as early in 1990. Strauss, C. \& Quinn, N. (1997) mentioned the practice of metaphors in understanding complex knowledge and analogical problem solving in understanding the human behaviour irrespective of their cultural background. Bargh, Barndollar 1996) suggested the use of conventional metaphors consciously in language processing would lead to subconscious activation of goals and motivation for example in a class room situation if low achievers are grouped with high achievers tend to use conventional metaphors in language processing could influence low achievers subconsciously to follow the same path inducing motivation as well as setting goals. Moser etal (2000) study revealed that metaphorical expressions used in self-concept studies were found to promote cognitive abilities of analogical reasoning. Further in his research study mentioned that metaphorical expressions used by individuals were found to enhance processes of knowledge 
acquisition and proved to be statistically significant. Lot of scientific evidences are drawn from scientific studies by (Sotillo et al., 2007) indicates that metaphors when used in communication or in language processing makes use of both the hemispheres of the brain for example right hemisphere showed preferential involvement in the processing of insignificant metaphors and the left hemisphere showed preferential involvement for processing salient metaphors.(Coulson\& Van Petten, 2007)study on metaphors revealed the involvement of right hemisphere of the brain in processing metaphors as it helps in representing mental schema relevant to the given information thus indicating metaphorical thought process as well as mental schema that is the cognitive structures complement one another. Another instant if a teacher explaining the concept of transportation uses the phrase "A Camel is a desert taxi". Here the teacher tries to bring the similarity between a taxi and Camel (an animal) used for transportation. The statement initiates a few of the cognitive patterns mentioned below:

$>$ Why Camel is used for transportation only in desert?

$>$ How the animal adapts to the desert condition?

$>$ Why can't a taxi used in deserts unlike in roads?

These patterns developed in the right hemisphere of the brain helps in processing metaphors (Coulson \& Van Petten, 2002). Based on the research studies conducted the following complementary model could be proposed to explain the interdependence of metaphorical thinking and cognitive structures.

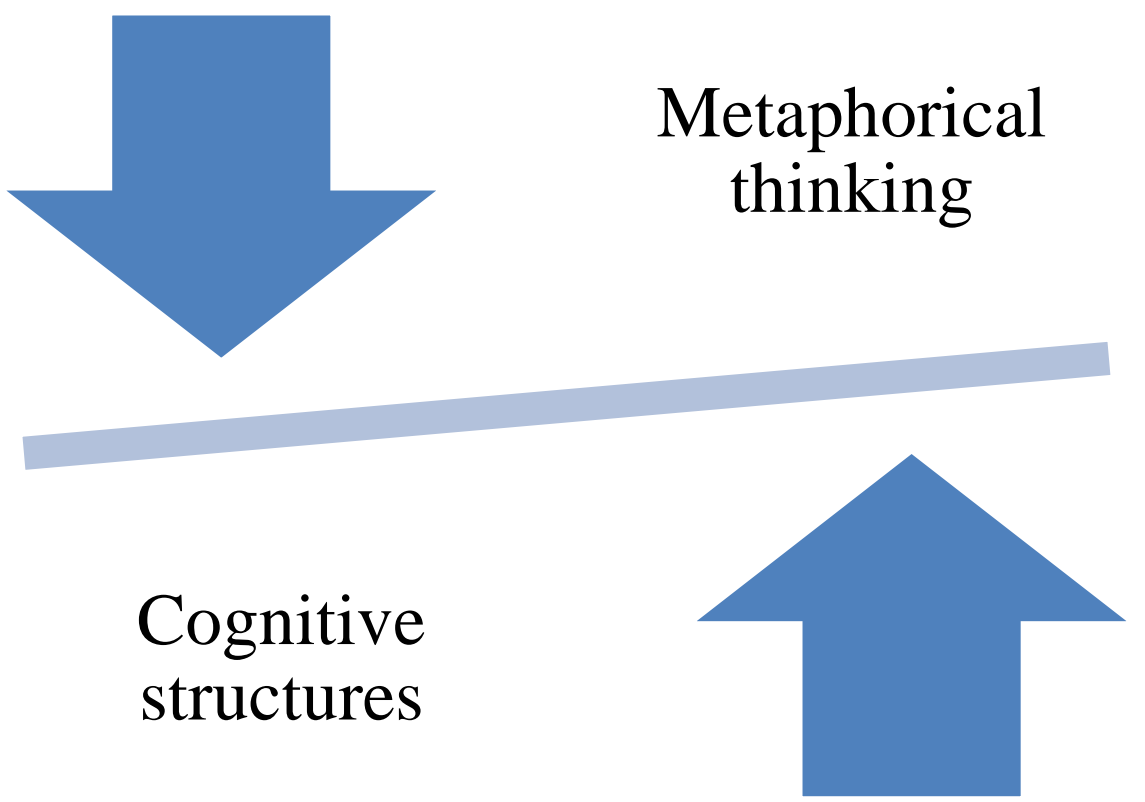

Therefore, planning a lesson implementing metaphoric thinking statements would enable the teacher to promote teaching learning process more effectively. $\mathrm{N}$ experiment was conducted among teachers by surveying them with a questionnaire evaluating the teacher's ability to nurture the capacity to enhance the formation of cognitive structures among the learners. (Borko. H andLivingston.C 1998). (Herrmann Ned 1999) suggested in his Brain dominance model that activities involving metaphorical thinking would promote different types of thinking namely: Analytical thinking, Sequential thinking, Interpersonal thinking as well as Imaginative thinking. Further it is observed that the implementation of metaphorical thinking statements in the lesson plan is in the form of thought provoking statements it is expected that it would facilitate the following learning outcomes among the students.

1. Creating questions of their own based on the information given. 
2. Obtaining supporting evidence to answer the question(s) by comparing with another universe which differs in their meaning.

3. explaining the evidence collected relevant to the questions.

4. Connecting the explanation to the knowledge obtained from the investigative process as mentioned in the second and the third step.

5. Creating an argument and justification for the explanation given. Lesson plan implementing metaphorical thinking in accordance to Bloom's Taxonomy develops the ability to analyse, synthesize, and evaluate information or new understandings indicate a high level of thinking.

Hence, the teacher should practice planning the lesson consciously so that the learners develop divergent thinking which would help them to ask their own questions and to learn the effective strategies for discovering the answers. Several research studies by (Chu, K.W.S.2009)proposed teacher training session by the process of using inquiry learning to ensure the maximal amount of resources creating the best learning scenarios.

\section{Training human brain to adopt Metaphorical thinking}

The human brain is an organic matter responsible for learning as long as its original constitution is inhibited. Some of the facts about brain based learning from the research conducted by Renate Nummela Caine and Geoffrey Caine (1997) are listed below.

$>$ The brain can perform several activities at once, like tasting and smelling simultaneously like parallel processor.

$>$ Learning engages both body and mind.

$>$ There always exists a natural urge to explore the meaning of the objects an individual perceives.

$>$ The brain has a tendency to understand the meaning of the given information through patterning.

$>$ Emotions are expressions of patterning.

$>$ The brain can process the given information as wholes and parts simultaneously.

$>$ It involves both focused attention and peripheral perception.

$>$ It involves both conscious and unconscious processes.

$>$ It is enhanced by challenge and inhibited by threat.

$>$ Each brain is unique.

By adopting Metaphorical thinking in teaching - learning process it could be suggested that the objectives of three instructional techniques associated with brain-based learning could be achieved similar to a musical orchestra. Nummela Caine and Geoffrey Caine (1997) stated that "Creating learning environments that fully immerse students in an educational experience." The second way is through alertness in a relaxed environment meaning "trying to eliminate fear in learners, while maintaining a highly challenging environment." Thirdly by enhancing the information processing ability that is by "allowing the learner to consolidate and internalize information by actively processing it." Any thought process taking place in the brain triggers the synthesis of neurotransmitters, being a continuous process taking place as long as breath continues. One such neurotransmitter that helps in learning is Norepinephrine. Several research studies had proved a significant role of neurotransmitters in promoting learning or Information processing ability. Parades, Daniel A. (2007) had shown that Nor-epinephrine (NE) plays a significant modulatory role in the acquisition of learning. Marvin Minsky (2011) pointed out that learning through connections, metaphors and visual associations to objects results in better understanding and is the more powerful way to learn. Nelson, (2008) in his book "Integrative and Comparative Biology pp48, 213-225 stated that learners to be successful innovators in science and mathematics learning process. A few recommended learning activities given below are peer teaching, Brainstorming, Competition, Cooperative games. Team assignments, checking work against a model, peer editing and discussion. Several research studies in recent years contributed to the power of metaphorical thinking in understanding the concepts of mathematics. For example a study was conducted by Jorge Soto- 
Andrade (2006) on 70 students to understand the concepts such as randomness, symmetry, infinity by means of group activities analysing problematic situation, coming out with different ideas, finding out the similarities between group activities and random walk. This concept establishes the idea of number theory that is numbers could be randomly arranged, symmetrically arranged as well as infinitely arranged. Thus from the above studies it was concluded that implementing metaphorical thinking as learning strategy could play a significant part in improving cognition in the school climate. To train human brain to think metaphorically depends on the teacher's capability to bring similarities

\section{Role of human brain in information processing}

The two hemispheres of the brain of the cerebral cortex are linked by corpus callosum through which they communicate. Corpus callosum is the structure composed of millions of axons that have their dendrites and terminal buttons projecting in both right and left hemispheres. Metaphorical thinking initiates synaptic activity in the axons which in turn enhances co-ordination between right and left hemispheres of the brain. Krish Sathian (2012) pointed out in a study that metaphor used in the textual message brings activation in the cerebral cortex enabling quick understanding of the information. In general, the speed of neural information processing is a complex process which involves a variety of constraints, including the time for electrochemical signals to traverse axons and dendrites, axonal myelination, the diffusion time of neurotransmitters across the synaptic cleft, differences in synaptic efficacy, the coherence of neural firing, the current availability of neurotransmitters, and the prior history of neuronal firing. This procedure may vary from one individual to another. Danielle S. Bassett (2010) pointed out that similar to computer chip performing a particular task human brain is also designed to perform a specific task depending on the biological development of the neurons. If the individuals are trained to think metaphorically, there is a probability of equalising the speed of neural information processing. Figure 1 represents the teaching-learning model which explains how to initiate metaphorical thinking. In this context, Human Brain and Computers are totally different from each other. To understand the function of the brain and computer, we need to look for analogy, problem solving ability and information processing ability being the components of metaphorical thinking. The following statements regarding the context (Human brain vs Computer) initiate Metaphorical thinking acting as stimulant to neurotransmitters across synaptic cleft.

\section{Objectives of the study}

* To find out the interdependence of content, activity and assessment delivery on cognitive structures.

* To find out the association between the dimensions of cognitive structures and gender.

* To find out to what extent the content, activity and assessment of lesson to be delivered possess variation in planning

\section{Research Questions}

* Is it necessary that the planning of a lesson should synchronize with content, activity and assessment?

* Does the gender influence in planning the lesson effectively to promote learning?

\section{Methodology}

* In order to meet the objectives as well as the research questions of the study a survey was conducted to find out the capability of the teachers in effectively delivering the lesson. A questionnaire was prepared to evaluate the ability of teachers in establishing cognitive structures among the learners. A proper planning of the lesson depends on the content, activity and assessment. Taking this view into account a total of 45 statements are framed with 15 statements each evaluating the three dimensions that is content, activity and assessment. Each statement is carefully framed to evaluate effectiveness with which the lesson is planned. Each statement is evaluated using five options: Not important (1), somewhat important (2), Important (3), Very important (4), extremely important (5). 
Respondents are requested to read carefully each and every statement and tick the appropriate option. The teachers were asked to read the statements to choose the appropriate answer which he/she thinks relevant. The data collected was subjected to data analysis. The first step was to calculate the Cronbach's Alpha on standardized Items found to be equal to 0.926 and the validity of the questionnaire was equal to 0.857 . Further analysis was carried out to answer the research questions stated above. In order to answer the first question multiple regression analysis was carried out to find out the interdependence of the content, activity and assessment in establishing cognitive structures among learners. The following table shows multiple regression " $R$ " values.

Table 1: To show the interdependence of content, activity and assessment with the cognitive structures.

\begin{tabular}{|l|l|l|l|l|}
\hline $\mathrm{N}$ & $\mathrm{R}_{1.234}$ & $\mathrm{R}_{1.23}$ & $\mathrm{R}_{1.34}$ & $\mathrm{R}_{1.24}$ \\
\hline 1149 & $1.00 * * *$ & $0.367 *$ & $0.382^{*}$ & $0.386^{*}$ \\
\hline
\end{tabular}

$* \mathrm{P}<0.05, * * \mathrm{P}<0.01, * * * \mathrm{P}<0.001, \mathrm{~N} . \mathrm{S}=$ Not Significant

From the table 1 and figure 1, the results clearly indicate that there is interdependence of cognitive structures on content, activity and assessment. It is necessary that the teacher carefully plans the lesson keeping in mind that at every stage of the development of the lesson, the teacher ensures that he/ she establishes cognitive structures among the learners by continuously emphasising on metaphorical thinking statements which enables the learner to think to find out the similarities between the content taught with that of illustration mentioned. For e.g. the learners confuse themselves in identifying a chemical change. In order to facilitate the identification the teacher explains the content by comparing the chemical change with the formation of fruit by using the metaphorical thinking statement "In chemical change a totally new product is formed from the elements, is this similar to the formation of fruit from a flower. What are the similarities between the two transformations though they are totally different?

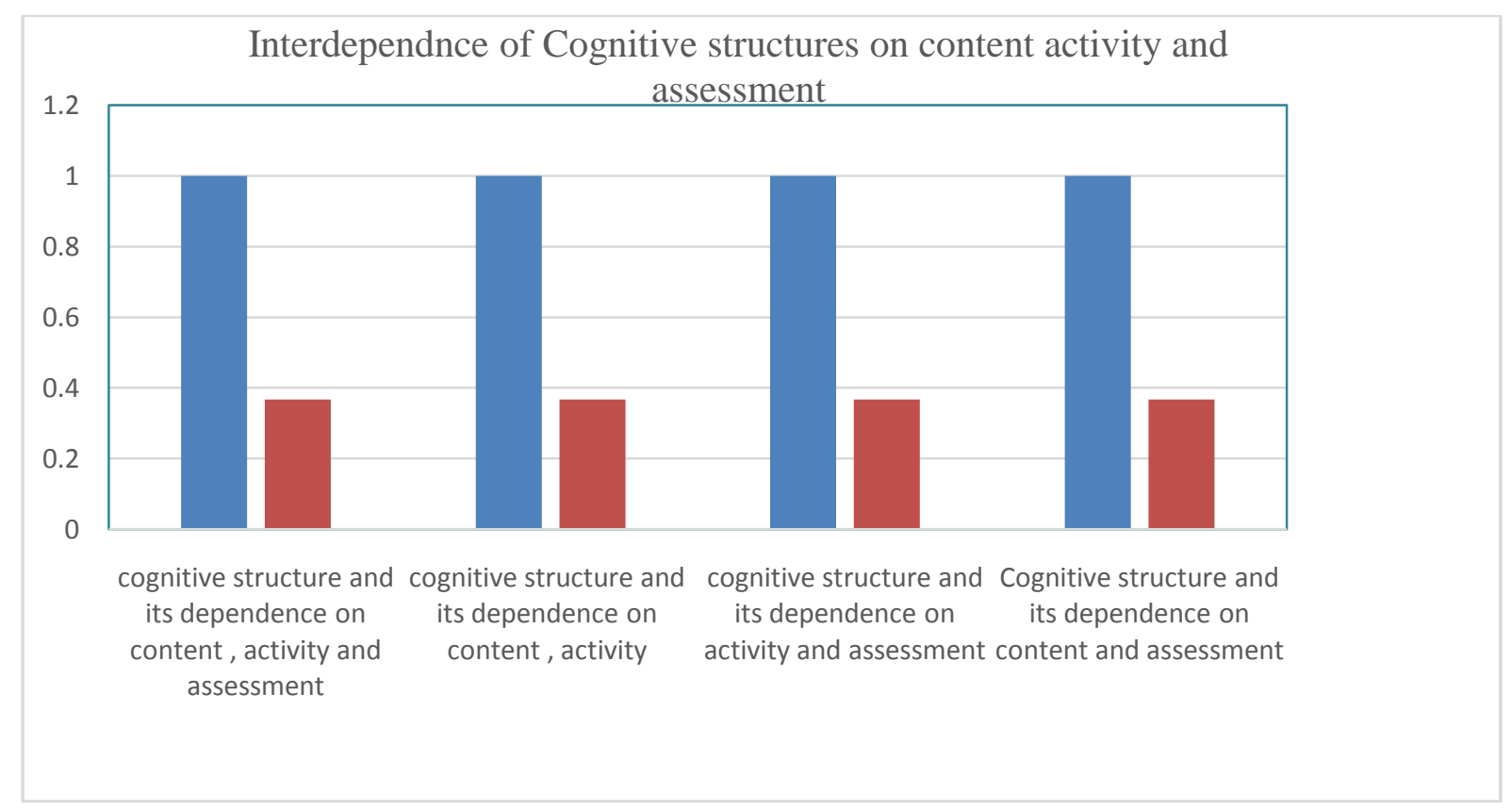

Figure 1: shows equal significance in planning content, activity and assessment in establishing cognitive structures.

In order to answer the second research question to find whether the gender plays any role in planning the lesson to effectively promote learning, Pearson chi-square test was calculated from the responses the result shown in the table 2 below. 
Table 2: To show the association of gender in planning the content, activity and assessment of a lesson.

\begin{tabular}{|l|l|l|l|l|l|}
\hline $\begin{array}{l}\text { Association of } \\
\text { gender } \\
\text { planning }\end{array}$ & $\begin{array}{l}\text { Pearson chi- } \\
\text { square }\end{array}$ & Cramer's V & Phi value & $\begin{array}{l}\text { Contingency } \\
\text { coefficient }\end{array}$ & $\begin{array}{l}\text { Total } \\
\text { respondents }\end{array}$ \\
\hline Content & $125.97 * * *$ & $0.234 * * *$ & $0.331 * * *$ & $0.314 * * *$ & \multirow{2}{*}{1149} \\
\hline Activity & $246.17 * * *$ & $0.327 * * *$ & $0.463 * * *$ & $0.420 * * *$ & $0.621 * * *$ \\
\hline Assessment & $720.72 * * *$ & $0.560 * * *$ & $0.792 * * *$ & 0.62 & \\
\hline
\end{tabular}

$* \mathrm{P}<0.05, * * \mathrm{P}<0.01, * * * \mathrm{P}<0.001, \mathrm{~N} . \mathrm{S}=$ Not Significant

From the table 2 it was shown that the Pearson chi-square value shows that gender has no role in planning the lesson in terms of content, activity and assessment.

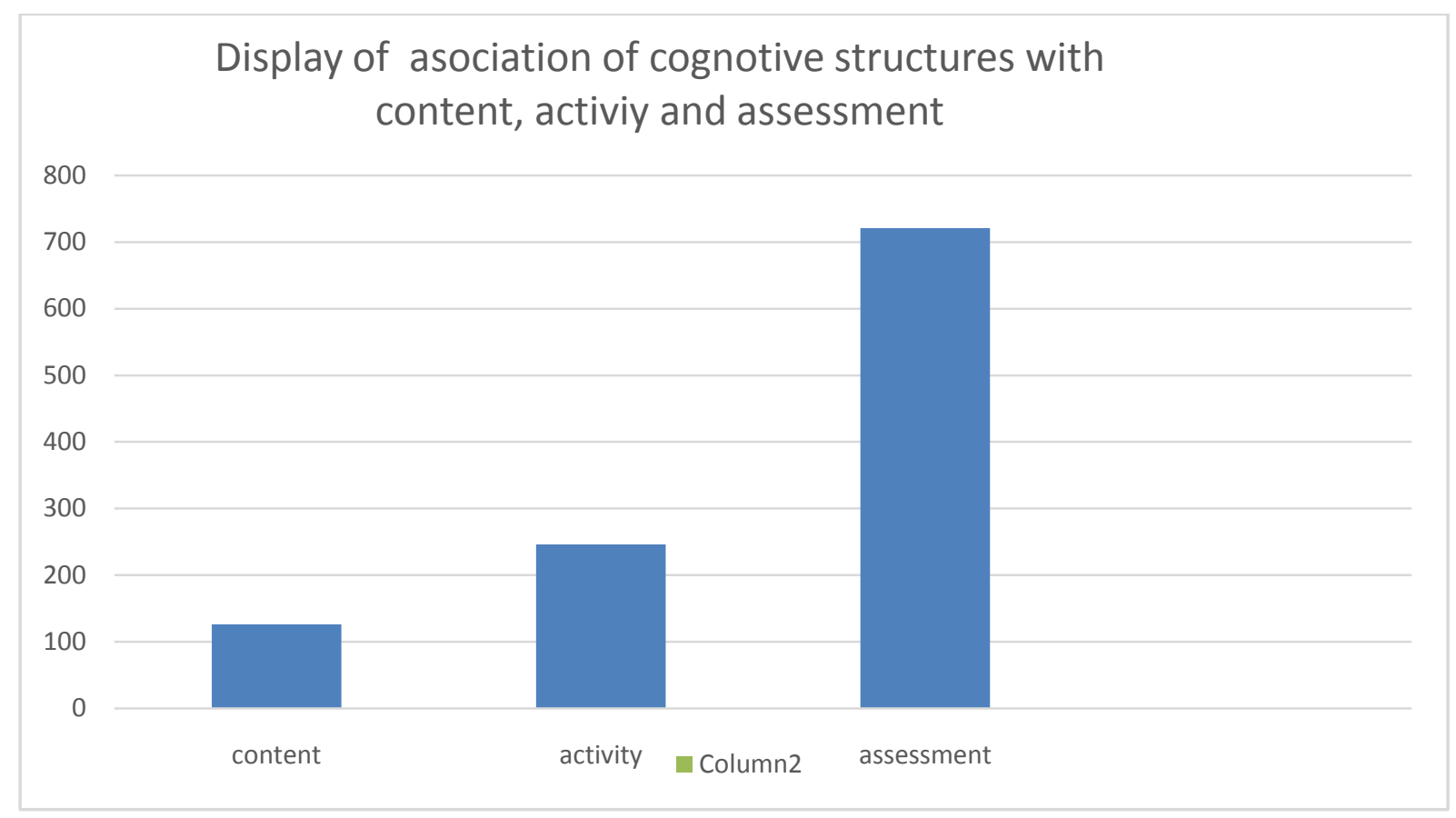

The results indicate that there is strong association between cognitive structures and the planning of content, activity and assessment of the lesson as the Pearson's chi-square values are significant at $\mathrm{p}<$ 0.001 level. It is also evident from the results that the teachers are advised to use as many metaphorical thinking statements as possible so that at every stage of the development of the lesson there exists a connection between content, activity and assessment so that the learners switch over from one structure to another effortlessly.

\section{Discussion}

Miller (2011) concluded in his study found that the children develop cognitive abilities through experiences relevant to a task as well as to a particular situations. Earlier researchers like Schunk (1996) proposed that learners who are information seekers in general exposed to information encode it through mental representations, relate it to the representations already stored in the memory and retrieve it when needed. According to Jean Piaget (1960) theory of intelligent thinking children interact with their environment in order to understand new fact by relating it to existing cognitive structures or whether these cognitive structures fit the new facts. The Piagetian idea of teaching thinking is employed in Cognitive acceleration in Science education (CASE) one of the acclaimed programmes used in U.K. In CASE the children are given the task information as well as similar task as test task to distinguish enables cognitive development by engaging the children in creative and critical thinking to understand the information. Baker, Gersten, \& Scanlon, (2002) suggested that 
cognitive structure support the learners to develop internal schema that enables the learner to solve complex tasks given to them. Rosenshine (1997) pointed out that cognitive structures are developed by equipping the learners to question the information targeted to them. It also increases the efficiency with which the learners approach the course content. Bulgren etal(1997) suggested strategies that teacher should focus on to enhance the course content by self-evaluation of the content and helping the learners to develop cognitive strategies by modelling the process of learning. In order to self evaluate the content the teacher should impose the following questions suggested below.

$>$ How important is the information proposed to my students?

$>$ Is the information provided relevant to the curriculum?

$>$ Will my students understand and apply the information outside class-room situations?

$>$ Which part of the information provided would be easy for students to understand?

$>$ Which part of the information needs more explanation with suitable examples as well as extra peer group activity?

$>$ How well the presentation of information to be delivered?

Therefore, the self - analysis of the content by the teachers used for knowledge transfer enables the learners to develop cognitive strategies which in turn increase the experience and the confidence of the learners to retain the targeted information. In the research the findings show that there is association between planning of content activity and assessment of the lesson irrespective of the gender of teachers. The research finding is supported by the Bulgren etal (1987) work conducted as early in 1987 suggested that the teacher should implement real life examples so that the teaching becomes more efficient as well as establishes the development of cognitive structures among learners enabling them to connect the content with real time life experiences.

\section{Conclusion}

Careful planning of the lesson implementing Metaphorical thinking based on content, activity and assessment would enhance the information processing ability among learners as it builds higher order thinking skills. The learners would able to understand, apply, analyse, synthesize and evaluate the knowledge presented to them. The following learning outcomes could be achieved by implementing a thought provoking lesson plan.

$>$ Learners generate new ideas analyse and evaluate to identify potential solutions to the given content.

$>$ By generating and refining ideas, the learners monitor their work and make adjustments as needed. This process would build self-regulation planning, monitoring, and evaluating their own thinking enable them to mould righteous attitude and acquisition of knowledge.

$>$ Develops thinking beyond the given concept thus enable to synthesize and evaluate new knowledge.

$>$ Lead to semantic understanding so that information is stored in long term memory.

$>$ Engages learners in thinking process which in turn develops intrinsic motivation.

\section{References}

1. Bargh, J. A. \& Barndollar, K. (1996). The psychology of action. Linking cognition and motivation to behavior (pp.457-481).New York: Guildford Press.

2. Betty K. Garner (2012), Getting to Got It!-Helping Struggling Students Learn How to Learn Association for supervision and curriculum development publication

3. Borko, H., \& Putnam, R. (1996). Learning to teach. In D. C. Berliner \& R. C. Calfee (Eds.), Handbook of educational psychology (pp. 673-708). New York, NY: Macmillan.

4. Borko, H., \& Putnam, R. (1996). Learning to teach. In D. C. Berliner \& R. C. Calfee (Eds.), Handbook of educational psychology (pp. 673-708). New York, NY: Macmillan.

5. Caine, G., Nummela-Caine, (1997) Education on the edge of possibility. Alexandria, VA: ASCD-Association for Supervision and Curriculum Development.

6. Caine, G., Nummela-Caine, R., \& Crowell, S. (1999) Mind shifts: A Brain-Based Process for Restructuring Schools and Renewing Education, 2nd edition. Tucson, AZ: Zephyr Press. 
7. Coulson S, Van Petten C. (2007) A special role for the right hemisphere in metaphor comprehension? ERP evidence from hemi field presentation. Brain Research. ;1146:128-145.

8. Coulson S, Van Petten C.(2002) Conceptual integration and metaphor: an ERP study. Memory \& Cognition. 2002;30:958-968.

9. Coulson, S., \& Van Petten, C. (2007). A special role for the right hemisphere in metaphor comprehension: ERP evidence from hemifield presentation. Brain Research, 1146, 128-145.

10. Danielle S. Bassett (2010) Efficient Physical Embedding of Topologically Complex Information Processing Networks in Brains and Computer Circuits, Computational Biology.

11. Jorge Soto-Andrade (2006) Metaphors and cognitive modes in the teaching learning of mathematics, Proceedings of CERME

12. Krish Sathian (2012) Metaphorically Feeling: Comprehending Textural Metaphors Activates Somatosensory Cortex. Brain and Language, 2012.

13. Marvin Minsky (2011), Semantic information processing, MIT press

14. Moser, K.S.; Clases, C. \& Wehner, T.(2000) Transdisciplinarity: Joint Problem-Solving among Science, Technology and Society. (Vol.I, pp.534-538). Zurich: Haffmans Sachbuch Verlag publication

15. Nelson, (2008), Supported teacher's collaborative inquiry, Teacher Education Journal, 35(1). 99-116.

16. Schmidt, G.L., DeBuse, C.J., \& Seger, C.A. (2007). Right hemisphere metaphor processing? Characterizing the lateralization of semantic processes, Brain andLanguage 100,

17. Schunk D.H. (1996) Learning theories $2^{\text {nd }}$ edition, Eaglewood Cliffs, New Jersy Merrill, an imprint of Pretice Hall.

18. Sotillo et al (2007), Neural activity associated with metaphor comprehension: spatial analysis. Neuroscience Letters

19. Strauss, C. \& Quinn, N. (Eds.) (1997). A Cognitive Theory of Cultural Meaning. Cambridge: Cambridge University Press. 